\title{
L'ús de les tècniques de reproducció assistida: una nova mirada sobre la reproducció i l'embaràs humà basada en el debat i l'argumentació.
}

Jaume Vila Gatius

INS Salas i Xandri (Sant Quirze del Vallès)

jvila16@xtec.cat

Alba Montalban Quesada

Departament de Didàctica de la Matemàtica i les Ciències Experimentals, UAB.

amontal3@xtec.cat

Resum - L'alfabetització científica promou apropar la ciència a tothom formant ciutadans amb capacitat de comprendre, decidir $\mathrm{i}$ actuar en temes científics. Per aconseguir-ho, una de les estratègies en l'àmbit pedagògic és vincular els coneixements científics a la vida quotidiana. En la següent recerca-acció, s'utilitzen les tècniques de reproducció assistida com a context social per teixir una seqüència didàctica sobre la reproducció humana. Aquesta proposta no només trenca amb formes més clàssiques d'ensenyar la reproducció, sinó que incorpora metodologies pròpies de la ciència com el treball cooperatiu, les controvèrsies socio-científiques, el debat i l'argumentació, tot sumant diverses competències científiques i adaptant parcialment els continguts a la teledocència. Els resultats mostren que l'alumnat és capaç de redactar texts argumentatius adequats, tant per l'estructura com per l'argumentació i incorporació de conceptes, destacant l'ús d'explicacions científiques per defensar la seva postura vers un dilema sociocientífic sobre les tècniques de reproducció assistida.

Paraules clau - controvèrsies socio-científiques, text argumentatiu, seqüència didàctica, treball cooperatiu, teledocència.

\section{The use of assisted reproductive technology: a new look at re- production and human pregnancy based on debate and argu- mentation.}

\begin{abstract}
Scientific literacy promotes putting science closer to people and educating citizens with ability to understand, decide and act in scientific issues. One strategy for that in pedagogy is to bind scientific knowledge and everyday life together. In the following action research, assisted reproductive technology is used as a social context so as to build a didactic sequence about human reproduction. This proposal not only breaks with more traditional ways of teaching reproduction but also incorporates scientific methodologies such as cooperative work, socio-scientific controversies, debate and argumentation, considering different scientific competences, and partially adapting the concepts in e-learning. The results show that the students are able to write proper argumentative texts, regarding structure, argumentation and concept incorporation, besides a remarkable use of scientific explanations to defend their stance on a socioscientific dilemma of assisted reproductive technology.
\end{abstract}

Keywords • socioscientific controversies, argumentative text, didactic sequence, cooperative work, e-learning. 


\section{INTRODUCCIÓ}

L'alfabetització científica, tot i ser un concepte clau en didàctica de les ciències, no es considera una realitat en la nostra societat, en la qual hi proliferen massa pseudociències $i$ teories conspiratives (Couso, 2017; Ezquerra et al., 2019). Desenvolupar una comprensió pública de ciència $\mathrm{i}$ tecnologia, és a dir, apropar la ciència a tothom és una tasca complicada i que necessita inversió i temps (Acevedo-Díaz, 2004). Una de les estratègies per aconseguir-ho en el món educatiu és vincular els coneixements científics a la vida quotidiana (Blanco-López et al., 2018). En altres paraules, buscar contextos propers a l'alumnat per tal que, en un marc acadèmic, trobi la motivació, necessitat $i$ utilitat d'aprendre ciència és un dels camins cap a l'alfabetització científica.

Si ens centrem en la biologia, un dels temes clau és la reproducció, tant cel-lular com a nivell d'organisme. Quan es parla de mitosi, meiosi o embaràs es mira la reproducció des de diferents punts de vista o en moments diversos d'un mateix esdeveniment. La reproducció humana, i en concret, l'embaràs, és el tema sobre el qual pivota la proposta didàctica de la present recerca-acció, la qual exposa una seqüència didàctica (SD) aplicada en dos grups classe de Biologia de primer de Batxillerat d'un Institut concertat de titularitat religiosa del centre d'una gran ciutat capital de comarca. Aquesta SD utilitza les Tècniques de Reproducció Assistida (TRA) com a context per tal de vincular ciència i societat.

A nivell metodològic, la SD incorpora, a part del treball cooperatiu, l'ús del debat sobre una controvèrsia socio-científica (CSC) i el text argumentatiu, els quals permeten una comprensió sobre els canals de comunicació propis de la ciència, sovint oblidats a l'aula. Tots dos formats es sustenten en la mateixa activitat cognitiva: l'argumentació, que es pot entendre com l'activitat de relacionar proves $\mathrm{i}$ models amb explicacions (Bravo, Puig \& Jiménez-Aleixandre, 2009). En el cas de la CSC, entesa com un dilema social amb implicacions en algun àmbit científic (Domènech, 2014; Farró, Lope, Marbà \& Oliveras, 2016), es busca una formació d'una ciutadania crítica a partir de contextos propers, actuals i controvertits a través del debat que mostra a l'alumnat que l'aprenentatge científic és una eina per prendre decisions en els assumptes públics científicotecnològics (Domènech-Casal \& Lope, 2016). D'altra banda, el text argumentatiu ajuda a entendre com funciona la pròpia ciència i facilita la comprensió dels coneixements científics en involucrar l'alumne/a en els instruments conceptuals i procedimentals de la matèria (Sardà \& Sanmartí, 2000). Les dues metodologies tenen un nexe d'unió en la SD d'aquesta recerca ja que utilitzen les TRA com a context.

\section{Les Tècniques de Reproducció Assistida}

Les TRA estan guanyant molt terreny en la nostra societat de forma sigil-losa ja que, segons les últimes dades publicades al 2019 pel Ministeri de Sanitat, l'any 2017 van ser responsables del 9\% dels naixements a Espanya (MSCBS, 2019). La tendència a l'alça dels últims anys, té moltes lectures socials $i$ econòmiques com ara l'allargament de l'edat de la maternitat en una societat centrada en el treball, o els grans beneficis de les clíniques privades, però també té múltiples enfocaments científics. Al cap i a la fi, les TRA només són un exemple més de com el coneixement científic i tecnològic es pot posar al servei de les necessitats humanes. A nivell acadèmic, el tractament de les TRA com a context a l'aula en aquesta SD permet, entre d'altres:

- Establir el marc necessari per estudiar l'embaràs humà.

- Construir una mirada amb perspectiva de gènere sobre la reproducció i la concepció.

- Generar debat i possibles CSC a l'aula.

- Treballar el text argumentatiu com a eina de comunicació científica.

Així doncs, les TRA són un context idoni per tractar no només els conceptes i les idees lligades a la reproducció i embaràs humà, sinó també un marc en el qual hi tenen cabuda el debat i el text argumentatiu, dues eines pròpies de la ciència.

El text argumentatiu fou l'eina seleccionada per valorar l'eficàcia de la UD. D'aquesta manera, la recerca es va centrar en els assaigs escrits per 
l'alumnat, definint dos objectius de recerca: analitzar l'estructura dels texts i analitzar i classificar els arguments emprats pels i les estudiants. Finalment, amb una mirada més genèrica, la recerca plantejada ha de permetre comprendre millor si el conjunt de la SD dissenyada i aplicada permet aprendre de forma efectiva l'ús del text argumentatiu en ciència i si la CSC i les TRA són un bon context d'aprenentatge per aquesta tipologia textual.

\section{SEQÜÈNCIA DIDÀCTICA}

La SD aplicada al centre fou dissenyada per abarcar els conceptes lligats a la reproducció i embaràs humà com ara la concepció, el desenvolupament fetal $\mathrm{i}$ organogènesi, el sistema endocrí, la mitosi i els cicles biològics, en un total de 13 sessions de 55 minuts. Tenint en compte que l'alumnat treballava amb el llibre "Nou Biocontext 1. Biologia" (Costa et al., 2016), es va utilitzar de punt de partida per iniciar la SD. També es va tenir en compte el cicle d'aprenentatge, els conceptes tractats prèviament, com ara el fet que la meiosi ja l'havien treballat, i les directrius pròpies del centre, com per exemple promoure el treball cooperatiu $i$ avaluar amb un examen final de tema.

\begin{tabular}{|l|l|}
\hline Seqüència Didàctica \\
Codis & Activitat \\
Act.1, & $\begin{array}{l}\text { Plantejament de diversos casos } \\
\text { I/GC, }\end{array}$ \\
$\begin{array}{l}\text { relacionats amb la reproducció } \\
\text { assistida per tal de veure les idees }\end{array}$ \\
Exp & $\begin{array}{l}\text { prèvies de l'alumnat, els } \\
\text { coneixements que tenen sobre } \\
\text { aquests temes i com es posicionen } \\
\text { de forma individual, per escrit, i } \\
\text { col-lectiva, oralment, en cada cas. }\end{array}$ \\
\hline $\begin{array}{l}\text { Act.2, } \\
\text { PG/GC, }\end{array}$ & $\begin{array}{l}\text { Explicació magistral participativa } \\
\text { sobre el sistema endocrí aplicat al } \\
\text { context de l'embaràs posant èmfasi } \\
\text { en el model estímul-receptor- }\end{array}$ \\
Int & $\begin{array}{l}\text { resposta. Introducció de la Síndrome } \\
\text { de l'Ovari Poliquístic com a activitat } \\
\text { d'estructuració per resoldre en grups } \\
\text { petits. }\end{array}$ \\
\hline
\end{tabular}

Act.3, Activitats d'aplicació del sistema en$P G / G C$, docrí en grups petits de forma escri1, ta: píndola del dia de després, antiApl conceptius hormonals, avortament per fàrmacs.

Act.4, Explicació magistral participativa GC, basada en micrografies i esquemes sobre els processos de mitosi, meiosi $1, \quad$ i els cicles biològics. Posant especial Int èmfasi en la importància de la mitosi $\mathrm{i}$ meiosi en la divisió cel-lular i el creixement i desenvolupament de l'organisme.

Act.5, Activitat d'estructuració i aplicació de PG/GC, cicles biològics: identificació de diversos cicles, mitosi $\mathrm{i}$ meiosi $\mathrm{i}$ 1, determinació del sexe de diversos Est/Apl éssers vius (ésser humà, medusa, algues, àfid pèsol) en petits grups.

Act.6, 3 grups d'experts (fecundació i PG, detecció / setmana 0-28 / 29-40 i part

i post-part): preparació d'una 2, presentació oral sobre el Int/Est desenvolupament embrionari posant èmfasi en la diferenciació cel-lular, l'organogènesi i el control hormonal, explicitant els canvis a nivell de cèl.lula i organisme.

Act.7, Presentació oral usant les TIC dels PG/GC, diversos grups. Auto i co-avaluació 1, Est (rúbrica).

Act.8, Explicació magistral participativa de GC, les diverses proves realitzades 1. durant l'embaràs, la determinació 1, dels grups sanguinis i $R h$ i les Int cèl-lules mare del cordó umbilical (aplicació de diferenciació cel-lular).

Act.9, Lectura d'un article i diverses dades I/PG/GC, sobre l'avortament i la mortalitat 1, del text augmentatiu, els tipus Int/Est d'arguments i l'estructura, i elaboració d'un text individual sobre el tema. 


\begin{tabular}{|c|c|}
\hline $\begin{array}{l}\text { PG/GC, } \\
1, \\
\text { Int/Est }\end{array}$ & $\begin{array}{l}\text { i cerca d'informació per preparar en } \\
\text { grups reduïts el debat sobre la CSC: } \\
\text { "la Sanitat Pública ha de costejar tots } \\
\text { els tractaments de reproducció } \\
\text { assistida". }\end{array}$ \\
\hline $\begin{array}{l}\text { Act.11, } \\
\text { GC, } \\
1, \text { Apl }\end{array}$ & $\begin{array}{l}\text { Debat de tota la classe sobre la CSC. } \\
\text { Activitat individual d'autoregulació } \\
\text { sobre la postura inicial i final i els }\end{array}$ \\
\hline $\begin{array}{l}\text { Act. } \\
\text { I, } \\
1, \\
\text { Apl }\end{array}$ & $\begin{array}{l}\text { Lectura d'una notícia relacionada } \\
\text { amb les TRA, comprensió lectora i } \\
\text { aplicació de continguts teòrics SD. } \\
\text { Elaboració d'un text argumentatiu per } \\
\text { justificar la posició individual sobre el } \\
\text { dilema de la CSC. }\end{array}$ \\
\hline
\end{tabular}

Taula 1: Taula resum de les activitats de la SD. Codi activitat: Act.1-12: número de l'activitat. Codi organització social a l'aula: I: individual, PG: petit grup, GC: grup classe. Codi temps: 1: una sessió, 2: dues sessions. Codi part del cicle d'aprenentatge dominant: Exp: exploració d'idees, Int: introducció de conceptes, Est: estructuració, Apl: aplicació.

Les TRA són el context principal de la SD, ja que s'utilitzen al llarg de tot el cicle d'aprenentatge (Taula 1). Tot i el seu pes en la proposta didàctica, sent clau en la CSC i el text argumentatiu, al llarg del cicle d'aprenentatge apareixen altres contextos com els mètodes anticonceptius i l'avortament.

\section{Treball cooperatiu}

Un cop introduïts els conceptes del sistema endocrí i la mitosi i el cicle biològic, es realitzen activitats d'estructuració i síntesi per tal de consolidar i transferir els conceptes apresos a altres contextos d'aprenentatge (Act.3 i 5, Taula 1). Aquestes actvitats, basades en contextos propers a l'alumnat com ara mètodes anticonceptius hormonal, l'avortament farmacològic o la Síndrome de l'Ovari Poliquístic, es duen a terme en petits grups, de $3 \circ 4$ alumnes, heterogenis per tal de fomentar el treball coopertiu. Al final de la classe, una posada en comú de les respostes serveix com a correcció i avaluació de la participació.

D'altra banda, els esdeveniments que ocorren durant l'embaràs, de la concepció al post-part, són la base per a la realització d'un treball i presentació oral (Act.6 i 7, Taula 1). Amb un format de grup d'experts, l'embaràs es divideix en 3 períodes, per tal de que cada grup, heterogeni i diferent que el de les activitats, presenti a la resta de la classe els esdeveniments més destacats i que trobin més interessants. L'avaluació té en compte el treball escrit i el suport de la presentació del grup i l'exposició oral de cada alumne/a.

\section{Controvèrsia sociocientífica}

En la SD plantejada, es dediquen dues sessions a la CSC "La Sanitat Pública ha de costejar tots els tractaments de reproducció assistida per a tothom que ho desitgi" (Act.10 i 11, Taula 1). La primera d'elles persegueix que l'alumnat busqui arguments a favor o en contra del plantejament de la CSC, mentre que la segona sessió consisteix en el debat amb tot el grup classe. Al final es realitza una activitat individual d'autoregulació sobre la postura inicial i final i els arguments rellevants. L'objectiu principal del debat és observar l'ús dels arguments per tal de comprovar que la CSC té diverses lectures (social, econòmica, legal...) més enllà de la científica.

\section{Text argumentatiu}

La SD incorpora dos texts argumentatius (Act.9 i 12, Taula 1). El primer, sobre l'avortament i la mortalitat materna, basat en la lectura d'un article de l'ONG Metges Sense Fronteres (MSF, 2018), serveix com a activitat introductòria del format, mentre que el segon forma part de l'activitat final de la SD i cal que l'alumne/a defensi amb arguments i conceptes científics, entre d'altres, la seva postura vers el dilema de la CSC. Aquests darreres texts inclosos en l'activitat de síntesi de la SD, es van analitzar per tal de comprovar si l'alumnat aprengué el format i l'ús d'aquesta tipologia textual pròpia de la ciència.

\section{Adaptació a la teledocència}

La clausura dels centres educatius decretada el 12 de Març de 2020 degut a la pandèmia de COVID-19 provocà que les 6 darreres sessions de la SD no es puguessin realitzar a l'aula pel que es van haver d'adaptar ràpidament a la teledocència. Els principals canvis van ser: 
- La finalització i entrega en línia del treball escrit i el suport de la presentació en grup sobre l'embaràs.

- L'aprenentatge autònom guiat amb el material d'aula sobre el text argumentatiu i l'entrega en línia de l'asssaig sobre l'avortament i la mortalitat materna.

- L'entrega en línia d'una activitat de preparació del debat amb l'explicació de diversos arguments (científics, socials, econòmics, legals $\mathrm{i}$ personals) a favor $\mathrm{o}$ en contra del dilema de la CSC. La celebració del debat es va suprimir.

- La realització en línia de l'activitat final la qual incorporava un text argumentatiu sobre la CSC del debat.

\section{METODOLOGIA}

La mostra analitzada són els texts argumentatius de l'activitat final, realitzats pels 23 alumnes de 16-17 anys que cursaven l'assignatura de Biologia en el centre on s'implementà la SD.

L'anàlisi dels texts inclou dues estratègies diferents $\mathrm{i}$ complementàries. La primera busca discernir l'estructura i els elements del text, mentre que la segona analitza el tipus d'arguments emprats. Per a l'estructura, tenint en compte estudis anteriors (Sardà \& Sanmartí, 2000), s'identifiquen els següents elements del text: introducció amb títol i presentació del dilema, cos amb arguments, dades, justificació i garantia, i conclusió amb refutació i, si cal, opinió personal. A més, es poden comptabilitzar el nombre de connectors emprats per l'alumnat per tal de donar cohesió al text. Per tal d'analitzar la validesa formal del text, es considera un assaig complet si compta, de forma explícita o implícita, amb 3 arguments, una jutificació i la conclusió.

D'altra banda, l'anàlisi i classificació dels arguments emprats seguint una codificació de dades qualitatives (Fernández, 2006) estableix 4 categories d'arguments bàsics: científics, socials, econòmics i legals. Dins de cada categoria, segons els texts dels i les estudiants, s'identifiquen diversos codis únics per cada argument.
Finalment, la codificació d'arguments generada a partir dels texts serveix com a base per comparar amb els arguments de l'activitat d'exploració (Act.1, Taula 1), en la qual l'alumnat es va posicionar, utilitzant les justificacions que va considerar, a favor o en contra de l'ús d'una TRA en una situació real. Aquests 6 casos plantejats inclouen realitats com ara les parelles homosexuals, famílies monomarentals, infertilitat, o el diagnòstic genètic preimplantacional en famílies amb malalties greus hereditàries. Amb la comparació dels arguments de la primera i la darrera activitat de la SD, es pot veure com evolucionen i inferir l'èxit de la pròpia proposta didàctica.

\section{RESULTATS}

\section{Anàlisi de l'estructura}

Dels 23 texts analitzats, 17 d'ells es consideren complets segons la validesa formal. Dels 6 incomplets, 2 no incorporen cap tipus de justificació, en 2 hi manca la conclusió i en els 2 restants no hi ha cap justificació ni conclusió.

D'altra banda, l'estudi dels elements del text mostra que només en 5 assaigs s'hi troba una garantia i en 9 una refutació, sent els dos elements menys freqüents, sense considerar el títol. L'opinió personal de l'autor/a del text s'observa en 13 dels 23 assaigs. De fet, l'ús de la primera persona en algun dels texts va més enllà de la seva opinió ja que de les 20 introduccions comptabilitzades, dues d'elles estan redactades en primera persona del singular amb frases com "en aquest text us intentaré explicar...". D'altra banda, en 7 de les introduccions observades no s'hi presenta el dilema de la CSC. En aquests casos, la introducció majoritàriament planteja l'ús de les TRA però en cap cas s'esmenta si el seu ús s'hauria d'incloure a la sanitat pública fet que era el dilema a debatre. Finalment, l'ús d'arguments (107 en total) i de dades (63), és força recurrent en el cos dels escrits de tot l'alumnat, de la mateixa manera que abunden els connectors, de 4 a 12 per text.

\section{Anàlisi dels arguments}

La codificació dels texts argumentatius de l'alumnat es tradueix en un total de 18 tipus 
d'arguments, gairebé la meitat científics (8). La segona categoria amb més arguments és la social, seguida de les explicacions de tipus econòmic i, finalment, els arguments legals. Tenint en compte les diverses argumentacions, la taxa d'èxit de les TRA és la més utilitzada (22), seguida del fet que la inclusió d'aquestes tècniques a la Sanitat Pública n'augmentaria la seva accessibilitat ja que moltes persones que no se les poden pagar s'hi podrien acollir (14) (Fig. 1). Aquest argument inclou frases com "molta més part de la població hi podria accedir" o "dóna oportunitats sigui quina sigui la seva situació econòmica". Finalment, el tercer argument més comú és el cost que tindria per l'administració pública (11) (Fig. 1).

$$
\begin{aligned}
& \text { Cientifics }\left\{\begin{array}{l}
\text { C1: taxa d'exit o efectivitat } \\
\text { C2: canvis tissulars } \\
\text { C3: menys errors genètics } \\
\text { C4: risc pacient } \\
\text { C5: fill/a ADN propi } \\
\text { C6: límit evolutiu } \\
\text { C7: decisió comitè bioètica } \\
\text { C8: altres }
\end{array}\right. \\
& \text { Socials }\left\{\begin{array}{l}
\text { S1: major accessibilitat } \\
\text { S2: la societat com a límit } \\
\text { S3: adopció } \\
\text { S4: augment natalitat } \\
\text { S5: altres }
\end{array}\right. \\
& \begin{array}{c}
\text { Econòmics } \\
\text {-E- }
\end{array}\left\{\begin{array}{l}
\text { E1: cost per la sanitat pública } \\
\text { E2: impostos } \\
\text { E3: alt preu de les tècniques }
\end{array}\right. \\
& \begin{array}{l}
\text { Legals } \\
\text { L- }
\end{array}\left\{\begin{array}{l}
\text { L1: llei } \\
\text { L2: dret a ser pare/mare }
\end{array}\right.
\end{aligned}
$$

Figura 1: Xarxa sistèmica dels arguments emprats en els texts argumentatius. A la dreta es mostra el nombre de vegades que apareix cada argument en el conjunt dels 23 texts analitzats.

\section{Evolució dels arguments en la SD}

Si els arguments codificats en la figura 1, s'apliquen en l'Act.1 de la SD -activitat d'exploració sobre diversos casos d'aplicació de les TRAs'observa una imatge que plasma l'evolució dels arguments al llarg de la SD (Fig. 2). Tot i que no són dues activitats iguals, ambdues propostes busquen que l'alumnat justifiqui la seva posició, envers una situació amb implicacions científiques i socials, amb arguments de qualsevol tipus. Així doncs, aquesta anàlisi permet determinar que els arguments socials, els més utilitzats a l'inici de la $\mathrm{SD}$, queden desbancats pels científics en l'Act.12 (Fig. 2). El lideratge social inicial es basava en arguments com que les TRA són l'única alternativa per ser pares/mares en els casos plantejats i que les TRA són de gran ajuda per diversos models de família com la monomarental/parental o el col-lectiu LGTBIQ+, arguments que pràcticament despareixen en l'activitat final de la SD i que inclou frases com "no cal tenir parella per criar i donar a llum un fill" o "una parella gai també hauria de poder tenir fills". Aquesta reducció de les justificacions socials, molt lligades a l'enunciat de cada situació de l'Act.1, es vincula a més amb l'augment d'arguments científics com la taxa d'èxit o el control de possible mutacions o errors genètics en els gàmetes 0 zigots (Fig. 1 i 2 ).

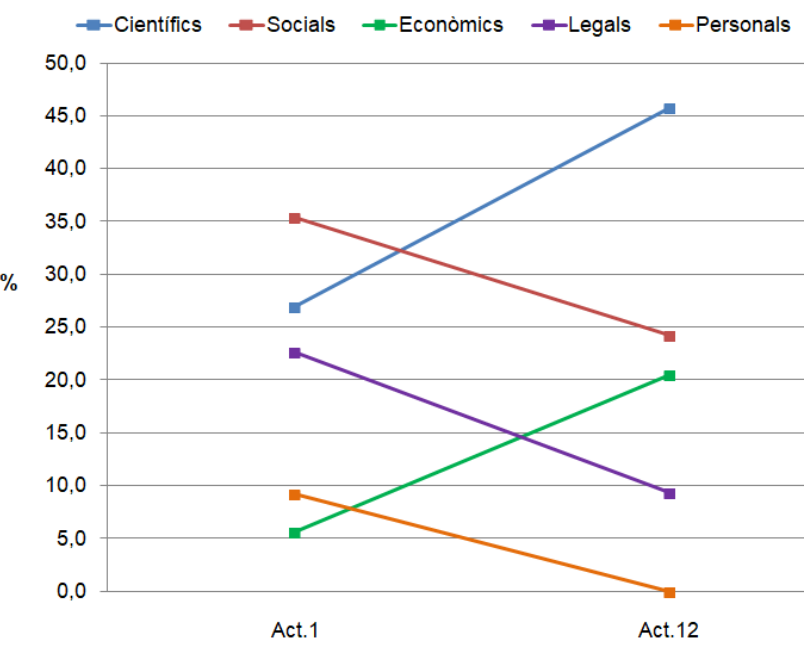

Figura 2: Gràfic de l'evolució dels arguments emprats per justificar la decisió presa en l'Act.1 i en els texts argumentatius (Act.12). Els arguments per categories es mostren en percentatge (recurrència de cada categoria respecte el total d'arguments en cada activitat).

D'altra banda, els arguments econòmics i els legals, inverteixen les seves tendències al llarg de la SD (Fig. 2). Aquest fet es deu principalment a la reducció en l'ús de l'argument $\mathrm{L} 2$, "dret a ser pare/mare", que passa de ser emprat per 14 alumnes a l'inici a només 4 a l'Act.12. Aquest suposat dret, el qual no està reconegut explícitament en cap llei, es pot deure a 
concepcions prèvies i després de la posada en comú de l'Act. 1 i d'altres activitats de la SD, queda reduït a 5 aparicions en els texts argumentatius. La disminució de les justificacions legals va de la mà de l'augment de les idees econòmiques, molt vinculades al dilema plantejat en la CSC i el text argumentatiu ja que la Sanitat Pública és una despesa o inversió de tota la societat.

Finalment, a l'inici de la SD hi apareixen arguments personals. Aquesta categoria extinta en l'Act. 12 recull 13 justificacions que no són més que judicis de valor o opinions usades com a arguments per defensar la postura de l'alumne/a, els quals estaven molt vinculats al rebuig a la gestació subrogada, un dels casos plantejats a l'Act.1, i que desapareix al final de la SD.

\section{CONCLUSIONS}

La SD plantejada en la present recerca-accció és una nova mirada pedagògica de la reproducció $\mathrm{i}$ embaràs humà. Aquest enfocament, centrat en les TRA, busca actualitzar els continguts d'acord amb la realitat social actual, trencant amb idees desfasades, o almenys revisables, com I'heteropatriarcat i l'amor romàntic com a punts de partida de la reproducció. A més a més, no només es tracta de posar les TRA al centre de la SD, sinó d'incloure de forma troncal el treball cooperatiu, el debat, les CSC i el text argumentatiu. Aquestes eines pedagògiques són clau per treballar les diverses dimensions $i$ competències científiques $i$, en aquesta SD, permeten no deixar de banda els conceptes teòrics de la reproducció, com la meiosi i la mitosi, o de l'embaràs, com l'organogènesi i el sistema endocrí. Addicionalment, temes com l'avortament farmacològic, els anticonceptius hormonals, la Síndrome de l'Ovari Poliquístic o les famílies monomarentals, ofereixen l'oportunitat de tractar el feminisme de forma transversal a l'aula. Aquesta SD, però, té molt camp per córrer en l'àmbit de la igualtat ja que les TRA obren camí per tractar no només la igualtat entre homes i dones, sinó incorporar la diversitat sexual a l'hora de parlar de reproducció $i$ embaràs humà. Cal ressaltar que aquests temes socials $i$ la $S D$ en general està dissenyada per primer de Batxillerat, però que tant l'enfocament pedagògic com els contextos serien traslladables a l'ESO. Probablement, modificant els continguts per tal d'adaptar-los al currículum d'aquesta etapa educativa, concretament al tema de la reproducció humana de tercer d'ESO, seria una SD interessant de desenvolupar amb alumnes de 14-15 anys, per aprendre canals de comunicació científics com el debat i el text argumentatiu. Finalment, tot i que la SD no estava organitzada per fer-la telemàticament, es va haver d'adaptar parcialment a la teledocència. Les diverses sessions adaptades van poder mantenir la seva coherència pedagògica, si bé el debat es va suprimir. Amb més temps $i$ amb el bagatge $i$ l'experiència amb diverses eines digitals, sempre i quan tot l'alumnat tingués accés a un fòrum en línia o una plataforma de videotrucades, es podria plantejar la celebració del debat de forma telemàtica en format reduït.

D'altra banda, l'anàlisi dels texts argumentatius inclosos en l'activitat final de síntesi mostra que l'alumnat ha estat capaç d'aplicar els seus coneixements en l'elaboració de texts argumentatius més complets i amb més idees científiques. Una primera lectura dels resultats mostra que els i les estudiants van incorporar satisfactòriament l'estructura i l'ús del text argumentatiu. El fet que gairebé el $75 \%$ dels texts analitzats es poden considerar complets des d'un punt de vista formal, tot $i$ la poca experiència $i$ bagatge acadèmic en aquesta tipologia textual per part de l'alumnat, demostra que el text argumentatiu és una eina a l'abast de tots/es els i les estudiants. Si bé és cert que els resultats són millorables, ja que la garantia i refutació, dos elements propis de l'argumentació científica, són dels elements menys freqüents en els texts, cal comprendre que l'aprenentatge d'un canal de comunicació científic com l'argumentació és complex i requereix temps. A més, el confinament $\mathrm{i}$ l'adaptació a la teledocència de forma precipitada van ser dos impediments en aquest aprenentatge, tot i que el seu impacte és difícilment quantificable. Cal tenir en compte també que el confinament va comportar l'anulació del debat, pel que aquest format propi de la ciència no va poder ser tractat degudament a l'aula, un dels objectius de la SD. 
La segona lectura dels resultats, l'anàlisi dels arguments, denota que l'alumnat és capaç d'incorporar arguments científics per defensar la seva postura en una CSC. L'augment de les idees científiques a llarg de la SD, sense deixar de banda altres arguments propis de qualsevol tema sociocientífic, juntament amb la riquesa d'arguments incorporats per l'alumnat demostra que la proposta didàctica i l'ús de les TRA com a context són una bona estratègia pedagògica per tractar la reproducció humana. Cal afegir que a l'inici de la SD un $9,2 \%$ dels arguments es consideren personals, és a dir, opinions o conviccions personals, i que aquest tipus d'argumentacions no apareixen als texts argumentatius finals. Aquest fet indica que els aprenentatges de la SD ajuden a desplaçar aquestes posicions més emocionals, les quals són substituides per evidències $\mathrm{i}$ coneixements més racionals i objectius, allunyant l'alumnat de posicions pròximes a la postveritat.

Així doncs, la SD aquí descrita és una eina per tractar d'una forma diferent la reproducció i embaràs humà a primer de Batxillerat. Les diverses activitats (Taula 1) i els resultats de l'anàlisi dels texts argumentatius (Fig. 1 i 2 ) mostren que les TRA són un context molt útil per tractar aquests temes, incorporant diverses eines de comunicació, competències i mirades transversals com el feminisme. A més a més, l'estratègia exposada fomenta el desenvolupament d'una competència científica per a la ciutadania, també anomenada Scitizenship, per tal de formar ciutadans amb capacitat de comprendre, decidir i actuar en temes científics (Domènech-Casal, 2018).

\section{AGRAÏMENTS}

Els autors d'aquest treball agraeixen a l'alumnat i professorat de l'institut on es va aplicar la SD el seu esforç, dedicació i atenció a totes les activitats. Agraïm també els consells i orientació en el disseny inicial de la SD de l'Anna Marbà $i$ els consells $i$ revisió per part de la Conxita Màrquez, membres del grup LIEC (Llenguatge i Ensenyament de les Ciències) de la Universitat Autònoma de Barcelona. Investigació finançada pel Ministeri d'Economia (PGC2018-096581-B-C21) i realitzada dintre del grup ACELEC (2017SGR1399).

\section{BIBLIOGRAFIA}

Acevedo-Díaz, J. A. (2004). Reflexiones sobre las finalidades de la enseñanza de las ciencias: educación científica para la ciudadanía. Revista Eureka sobre enseñanza y divulgación de las ciencias, 1(1), 3-16.

Blanco-López, Á., Martínez-Peña, B. \& Jiménez-Liso, R. (2018). ¿Puede la investigación iluminar el cambio educativo?. Ápice. Revista de Educación Científica, 21(2), 15-28.

Bravo, B., Puig, B., \& Jiménez-Aleixandre, M. P. (2009). Competencias en el uso de pruebas en argumentación. Educación química, 20(2), 137-142.

Costa, M., Grau, R., Llobera, M., Llort, J. M., de Manuel, J., Molina, J., Montserrat, P., \& Padrosa, T. (2016). Nou Biocontext 1. Biologia. (1 ed.). Teide.

Couso, D. (2017). Per a què estem a STEM? Un intent de definir l'alfabetització STEM per a tothom i amb valors. Ciències, 3, 22-30.

Domènech, A. (2014). L'ús de les controvèrsies sociocientífiques per promoure la competència científica a l'educació secundària: el cas de la medicalització $i$ el TDA-H. (Tesis doctoral). Universitat Autònoma de Barcelona, Barcelona.

Domènech-Casal, J. (2018). Comprender, Decidir y Actuar: una propuesta-marco de Competencia Científica para la Ciudadanía. Revista Eureka sobre enseñanza y divulgación de las ciencias, 15(1), 1105.

Domènech-Casal, J., \& Lope, S. (2016). Les Jornades de controvèrsia sòcio-científica i recerca i innovació responsables: ciències per a qüestionar i canviar el món. Pensar, comprendre, decidir. Ciències, 30, 29-31.

Ezquerra, A., Mafokozi, J., Campillejo, A., BenéitezVillamor, A., \& Morcillo-Ortega, J. (2019). Tendencias de las investigaciones sobre la ciencia presente en la sociedad: una revisión sistemática. Enseñanza de las Ciencias. Revista de investigación y experiencias didácticas, 37(3), 31-47.

Farró, L., Lope, S., Marbà, A. \& Oliveras, B. (2016). Les controvèrsies sòcio-científiques com a contextos d'aprenentatge i comunicació a l'aula. Anàlisi de crítica de la informació i habilitats comunicatives. Ciències, $30,39-46$.

Fernández, L. (2006). ¿Cómo analizar datos cualitativos. Butlletí LaRecerca, 6, 1-13. 
MSF. (2018). Las consecuencias del aborto no seguro. Recuperat de: https://www.msf.es/las-consecuenciasdel-aborto-no-seguro.

MSCBS. (2019). Se mantienen los tratamientos de Fecundación In Vitro y disminuyen los de Inseminación Artificial en 2017. Recuperat de:
https://www.mscbs.gob.es/gabinete/notasPrensa.do?i $d=4691$.

Sardà, A. \& Sanmartí, N. (2000). Ensenyar a argumentar científicament: un repte de les classes de ciències. Enseñanza de las Ciencias, 18(3), 405-422. 